\title{
CHRONOLOGY OF EARLY SCYTHIAN COMPLEXES IN THE INSULAR AREA OF THE DON RIVER DELTA ${ }^{1}$
}

\author{
Mikhail Yu. Rusakov \\ Southern Scientific Center, RAS, Rostov-on-Don, Russian Federation
}

\begin{abstract}
The paper deals with the chronology of Early Scythian burial complexes as well as random finds of the same period from the insular area of the Don river delta. 4 Early Scythian burials are known at the moment: Malakhov Erik II burial complex which is dated by the author to the first half of the $6^{\text {th }}$ century BC on the basis of analysis of the funeral set; burial 108 of the Krest burial mound dating back to the end of the $7^{\text {th }}$ - beginning of the $6^{\text {th }}$ centuries BC on the basis of the analogies of the quiver set; burial 9 of barrow 136 of the Elizavetovskiy burial mound dating back to the first half of the $6^{\text {th }}$ century $\mathrm{BC}$, according to its stratigraphy, burial rite and grave goods; and burial 10 of barrow 136 from the same burial mound dating back to the end of the $7^{\text {th }}$ century $\mathrm{BC}$, according to the grave goods. The random finds from the area under consideration include such objects of interest as two cross plaques made of bronze and an Ionian red-clay juglet. As for the cross plaques, some specialists date them back to the first half of the $6^{\text {th }}$ century BC, while the others - to the second half of the same century. We suppose that these cross plaques from the Don river delta can be dated not later than to $625 \mathrm{BC}$, and the Ionian juglet - to the first half of the $6^{\text {th }}$ century BC. The analysis of archaeological sources let us make conclusion that Early Scythian burial sites had existed in the insular part of the Don River delta from the end of the $7^{\text {th }}$ century BC to the middle of the $6^{\text {th }}$ century BC, which had been the time of existence of the Early Scythian culture in the Lower Don region.
\end{abstract}

Key words: Lower Don region, Don river delta, Early Scythian culture, burial complex, imported Greek ceramics, cross plaque.

Citation. Rusakov M.Yu., 2018. Chronology of Early Scythian Complexes in the Insular Area of the Don River Delta. The Lower Volga Archaeological Bulletin, vol. 17, no. 2, pp. 18-31. (in Russian). DOI: https://doi.org/ 10.15688/nav.jvolsu.2018.2.2

УДК $902 / 904$

ББК 63.4

Дата поступления статьи: 11.09.2018 Дата принятия статьи: 01.11.2018

\section{ХРОНОЛОГИЯ РАННЕСКИФСКИХ КОМПЛЕКСОВ ОСТРОВНОЙ ЧАСТИ ДЕЛЬТЫ ДОНА ${ }^{1}$}

\author{
Михаил Юрьевич Русаков \\ Южный научный центр РАН, г. Ростов-на-Дону, Российская Федерация
}

\begin{abstract}
Аннотация. В статье рассматривается хронология погребальных комплексов раннескифского времени, а также случайных находок того же периода, обнаруженных в островной части дельты Дона. Всего в настоящее время известно 4 раннескифских погребения: Малахов Ерик II, который на основании анализа вещевого комплекса датирован автором статьи первой половиной VI в. до н.э.; погр. 108 могильника «Крест», отнесенное на основании аналогий колчанного набора к рубежу VII-VI вв. до н.э.; погр. 9 кург. 136 Елизаветовского могильника, датирующегося на основании стратиграфии, погребального обряда и инвентаря первой половиной VI в. до н.э.; погр. 10 кург. 136 Елизаветовского могильника, на основании погребального инвентаря получившего дату - конец VII в. до н.э. В числе случайных находок, обнаруженных в рассматриваемом регионе, нужно отметить две бронзовые крестовидные бляхи и ионийский красноглиняный кувшинчик. Мнения специалистов касательно датировки крестовидных блях на данный момент сильно расходятся - их относят как к первой, так и ко второй половине VI в. до н.э. Автор считает, что крестовидные бляхи из дельты Дона могут быть датированы не позднее третьей четверти VI в. до н.э., а ионийский красноглиняный кувшинчик - в пределах первой половины VI в. до н.э. На основе проведенного анализа археологических источников
\end{abstract}


можно сделать вывод, что памятники раннескифского времени появляются на островной части дельты Дона в конце VII в. до н.э. и существуют до середины VI в. до н.э., что укладывается во временные рамки существования раннескифской культуры на Нижнем Дону.

Ключевые слова: Нижний Дон, дельта Дона, раннескифская культура, погребальный комплекс, импортная греческая керамика, крестовидная бляха.

Цитирование. Русаков М. Ю., 2018. Хронология раннескифских комплексов островной части дельты Дона // Нижневолжский археологический вестник. Т. 17, № 2. C. 18-31. DOI: https://doi.org/10.15688/ nav.jvolsu.2018.2.2

Устьевая область реки Дон с древних времен является местом соприкосновения культур. В силу удобного географического положения и существования здесь еще с эпохи бронзы переправы в скифское время данная территория приобретает стратегическое значение как для эллинов, так и для скифов.

На островной части дельты Дона за время исследований были обнаружены погребальные комплексы разных эпох, начиная с ранней бронзы и заканчивая казачьим временем. Именно поэтому до недавних пор обращало на себя внимание полное отсутствие там раннескифских погребений [Копылов, Русаков, 2017 , с. 282], особенно учитывая несколько случайных находок эпохи скифской архаики и высокую концентрацию погребальных комплексов этого времени как на левом, так и на правом берегах устьевой области Дона.

Первый погребальный комплекс раннескифского времени в островной части дельты Дона был открыт при исследовании поселения эпохи поздней бронзы Малахов Ерик II (рис. 2). Погребение было впущено в культурный слой поселения [Копылов, Коваленко, 2006, с. 181]. Могильная яма имела форму вытянутого прямоугольника со скругленными короткими сторонами и длинной осью была ориентирована по линии запад-восток (рис. 2,1). На дне находились остатки костяка женщины 25-30 лет, который, судя по расположению сохранившихся костей, лежал на спине в вытянутом положении, головой на восток. Рядом с правым локтевым суставом находились остатки напутственной пищи в виде кости крупного животного. У правого бедра располагался погребальный инвентарь, представленный лепным лощеным сосудом и остатками колчанного набора. Лепной лощеный сосуд с высоким горлом, отогнутым наружу венчиком и скругленным верхним краем имеет выраженные округлые плечики и слегка вогнутое дно (рис. 2,3). На горле сосу- да слабо читаются вертикальные зигзаги, нанесенные темной краской. Полностью орнаментальная композиция не восстанавливается из-за плохой сохранности поверхности горла сосуда. Колчанный набор представлен бронзовыми втульчатыми наконечниками стрел, два из которых двулопастные (рис. 2,2д-e), один трехгранный с короткой головкой (рис. 2,2a) и три трехлопастные (рис. 2,26-2). Характер инвентаря позволил авторам раскопок датировать комплекс первой третью VI в. до н.э. [Копылов, Коваленко, 2006, с. 183].

Наконечник стрелы, аналогичный трехгранному, был обнаружен в погр. 4 кург. 7 Высочино-I, датируемом авторами раскопок первой половиной VI в. до н.э. [Кореняко, Лукьяшко, 1982, c. 152-153]. Трехлопастные наконечники стрел находят аналогии в погр. 5 кург. 24 могильника Новоалександровка-І и погр. 10 кург. 2 могильника Бушуйка. В последнем погребении, кроме того, представлена архаическая столовая амфора (рис. 6,1), которая В.П. Копыловым отнесена к милетской продукции и датирована не позднее середины VI в. до н.э. [Копылов, 2003, c. 136]. Таким образом, все указанные комплексы, включая Малахов Ерик II, следует датировать первой половиной VI в. до н.э.

В 2009 г. Р.В. Прокофьевым была исследована дюна ${ }^{2}$, расположенная к северу от х. Дугино, который автор раскопок обозначил как могильник «Крест» [Прокофьев, 2014, c. 67-69]. В центральной его части было открыто погр. 108, расположенное в связке могильных ям шести разновременных погребений и отнесенное автором раскопок к раннескифскому времени (рис. 3,1). Форма могильной ямы не прослежена. Погребенный мужчина 25-35 лет располагался в вытянутом положении, головой на запад. В районе левого бедра погребенного были обнаружены остатки колчанного набора, состоящего из 22 бронзовых втульчатых наконечников стрел 
(рис. 3,2), среди них: 5 двухлопастных (риc. 3,2a-3,2d), 4 из которых с шипом на втулке, 14 трехлопастных (рис. 3,2e-3,2y), 11 из которых с шипом на втулке, и 3 наконечника с трехгранной головкой (рис. $3,2 \phi-3,2 u), 2$ из которых с шипом. Погребение датировано автором раскопок второй половиной VII - первой половиной VI в. до н.э. [Прокофьев, 2014, с. 69].

Колчанный набор погр. 108 находит аналогии с колчанным набором южной могилы кург. 1 Краснознаменского могильника, а на Нижнем Дону - с наконечниками стрел из погр. 8 кург. 7 могильника Новоалександровка-I (авторы раскопок датировали данный комплекс второй половиной VI в. до н.э. [Кореняко, Лукьяшко, 1982, с. 160]), в инвентаре которого также присутствует милетская транспортная амфора (рис. 6,2). Р.М. Кук и П. Дюпон относят данный тип амфор ко второй - третьей четверти VI в. до н.э. [Cook, Dupont, 1998, с. $170-171$, рис. $23.7 \mathrm{~b}]$, С.Ю. Монахов - к середине VI в. до н.э. [Монахов, 2003, с. 32]. Совсем иную дату предлагает Ю. Сезгин. Последние исследования амфорной тары Милета позволили ему существенно удревнить датировки: так, самый ранний вариант архаического типа милетских амфор, по мнению исследователя, существует в 700-625 гг. до н.э. [Sezgin, 2012, с. 160]. Для сравнения: у Кука и Дюпона этот же тип бытует с конца VII до первой четверти VI вв. до н.э. [Cook, Dupont, 1998 , с. $170-171$, рис. $23,7 a]$. Амфора из Новоалександровки отнесена Сезгином к типу MIL2 и датирована 650-600 гг. до н.э. [Sezgin, 2012, с. 160]. Эту же дату предлагает и М.Н. Дараган, отметив, что амфоры указанного типа не встречаются в комплексах VI в. до н.э. [Дараган, 2010, с. 189]. Опираясь на достаточно противоречивые датировки, предложенные исследователями для милетской амфоры, погр. 8 кург. 7 могильника Новоалександровка-І предпочтительнее датировать рубежом VII-VI вв. до н.э. Подобным образом мы предлагаем датировать и погр. 108 могильника «Крест».

Еще два раннескифских погребальных комплекса были впущены в кург. 136, расположенный в Восточной части Елизаветовского могильника (рис. 4). Погребение 9 обнаружено в центральной части кургана в связке могильных ям (рис. 4,1 ). Судя по сохранившейся час- ти, могильная яма имела вытянутую форму с закругленными углами и была ориентирована длинной осью по линии восток-северо-восток запад-юго-запад. На дне находился костяк взрослого человека (женщина 25-30 лет), ориентированный головой на запад-юго-запад. Возле левой бедренной кости располагались два железных втульчатых наконечника стрел (рис. 4,2). Один из них, двухлопастной, имеет головку ромбовидной формы и длинную втулку, внутри которой прослеживались следы древка. Второй наконечник имеет трехлопастную, сильно корродированную головку и длинную втулку, внутри которой также прослеживались следы древка. Форма наконечника позволяет говорить, что он был слегка изогнут в древности. В ногах погребенного были прослежены остатки древесного тлена, которые могут быть связаны с несохранившимся деревянным сосудом. Дату погребения - первая половина VI в. до н.э. - позволяет определить двухлопастной железный наконечник стрелы, аналогичный наконечнику, обнаруженному в погр. 4 кург. 7 могильника Высочино-I [Кореняко, Лукьяшко, 1982, с. 152-153].

Погребение 10 также находилось в связке ям (рис. 4,1$)$. Кости ног погребенного частично находились под костяком погребения 9. Границы могильной ямы не прослеживались. Погребенный, судя по размерам костей - подросток, лежал на спине в вытянутом положении головой на северо-запад. Руки были вытянуты вдоль туловища, ноги были также вытянуты и сведены в стопах. Нижняя часть позвоночника и тазовые кости просели и располагались ниже остальных костей, поскольку в данном месте находилась могильная яма более раннего погребения 13. Следов подстилки и перекрытия в погр. 10 не прослеживалось. Рядом с черепом погребенного стоял лепной плоскодонный сосуд со слегка отогнутым наружу венчиком, имеющим слив (рис. 4,3). Часть его верхнего края была утрачена в древности.

Аналогичный сосуд со сливом был обнаружен И.Б. Брашинским в погр. 1 кург. 5 на западной окраине г. Ростова-на-Дону [Брашинский, 1973 , с. $54-57$, рис. 20]. В этом погребении также были встречены бронзовое зеркало с вертикальным бортиком и петельчатой ручкой на тыльной стороне, каменное блюдо и свинцовое пряслице. Погребальный обряд и 
характер сопровождающего инвентаря позволили И.Б. Брашинскому датировать это погребение VI в. до н.э. На данный момент бронзовые зеркала данного типа Т.М. Кузнецовой датируются VII в. до н.э. [Кузнецова, 2010, c. 232, 234]. Учитывая, что на сегодняшний день все надежно датированные комплексы на Нижнем Дону относятся ко второй половине VII века до н.э., причем тяготеют к концу столетия [Копылов, Русаков, 2014, с. 92], нам представляется, что погр. 1 кург. 5 на западной окраине г. Ростова-на-Дону, содержащее бронзовое зеркало, и, по аналогии с ним, погр. 10 кург. 136 Елизаветовского могильника следует датировать концом VII в. до н.э.

Помимо раннескифских погребальных комплексов, в островной части дельты Дона были также обнаружены случайные находки предметов скифской архаики, среди них: 2 бронзовые крестовидные бляхи, ионийский кувшинчик, а также единичные находки раннескифских наконечников стрел.

Первая крестовидная бляха была обнаружена в 1984 г. В.В. Чалым во время археологических разведок в районе х. Дугино [Копылов, 1992, с. 84, рис. 1,5] (рис. 5,1). Боковые и нижний выступы бляхи образованы головами хищных птиц (1 группа 3-й тип по Ю.Б. Полидовичу [Полидович, 2009, с. 477-478, 480]), в центре изображен свернувшийся хищник, вписанный в круг. Верхний выступ прямоугольной формы украшен тремя полосами ленточного орнамента. С обратной стороны к бляхе прикреплены две прямоугольные скобы для продевания ремня. Бляха с аналогичным сюжетом, но с литейными дефектами, была найдена в 2005 г. в дельте Дона к югу от хутора Полушкина и датирована Л.С. Ильюковым первой половиной VI в. до н.э. [Ильюков, 2016, с. 82] (рис. 5,2).

Помимо названных, в Северном Причерноморье нам известно еще 3 крестовидные бляхи аналогичного облика - из погр. 12 Ольвийского некрополя, погр. 3 кург. 3 могильника Аксай-І и из курганного могильника в Бырсешти (Румыния).

Ольвийская бляха неоднократно становилась объектом внимания исследователей (рис. 5,4). От блях, обнаруженных в дельте Дона, ее отличает оформление верхнего выступа, украшенного головами баранов. Датиров- ка ольвийской бляхи разнится: Б.Н. Граков относил ее к началу VI в. до н.э. [Граков, 1947, с. 32, рис. 4], С.И. Капошина датировала погребение, из которого происходит бляха, концом VI началом V вв. до н.э. При этом исследователь отметила, что «художественное изделие могло бытовать некоторое время до того, как попало в могилу», а временем его изготовления предложила считать вторую половину VI в. до н.э. [Капошина, 1956, с. 175-176]. А.С. Островерхов полагает, что бляху из Ольвии и аналогичные ей изделия предпочтительнее датировать в пределах первой половины V в. до н.э. [Островерхов, 1994, с. 62] Противоположного мнения придерживается С.В. Полин, который на основании анализа колчанного набора датировал погр. 12 временем не позднее второй четверти VI в. до н.э. [Полин, 1987, с. 29, рис. 8].

Из погр. 3 кург. 3 могильника Аксай-I происходит фрагментированная крестовидная бляха (рис. 5,5), сохранившаяся нижняя часть которой идентична бляхам из дельты Дона и Ольвийского некрополя. Нужно отметить, что это единственная на данный момент находка крестовидной бляхи в комплексе с греческой импортной керамикой. Ионийская столовая амфора из погребения авторами раскопок датирована второй половиной VI в. до н.э. [Дьяченко и др., 1999, с. 96, рис. 5] (рис. 6,3). А.Ю. Алексеев и М.Ю. Вахтина датируют амфору 560-500 гг. до н.э., а само погребение, на основании комплекса вещей, серединой - третьей четвертью VI в. до н.э. [Алексеев, 2003, с. 202]. В.П. Копыловым была предложена другая дата - первая половина VI в. до н.э. [Копылов, 2001, с. 22]. С ним согласна М.Н. Дараган, которая указывает, что Е. Вальтер-Кариди датирует амфоры, аналогичные сосуду из погр. 3, первой половиной VI в. до н.э. [Дараган, 2010, с. 194]. К этому же времени С.В. Полин относит колчанный набор указанного погребения, где соседствуют наконечники первой и второй хронологических групп [Полин, 1987, с. 31].

Крестовидная бляха из могильника Бырсешти внешне отличается от двух блях, происходящих из дельты Дона (рис. 5,6). Нижний и боковые выступы также образованы головами хищных птиц, однако верхний выступ орнаментирован фигурами копытных животных, а свернувшийся хищник в центре бляхи обращен в 
M.Yu. Rusakov. Chronology of Early Scythian Complexes in the Insular Area of the Don River Delta

другую сторону и не заключен в круг. Бляха из Бырсешти отнесена Д. Берчу, наряду с другими предметами скифской архаики с территории Румынии, к середине VI - началу V в. до н. э. [Берчу, 2008, с. 151-152].

По нашему мнению, наиболее точную и узкую дату крестовидным бляхам, о которых шла речь выше, дает ионийская столовая амфора из могильника Аксай-I. Однако исследователи на данный момент сильно расходятся в ее датировке - от первой до второй половины VI в. до н.э. На наш взгляд, учитывая сложившуюся ситуацию, крестовидные бляхи из дельты Дона могут быть датированы временем не позднее третьей четверти VI в. до н.э.

Еще одна случайная находка, происходящая из островной части дельты Дона - ионийский кувшинчик из разрушенного погребения в районе х. Дугино (рис. 5,3). Судя по сохранившейся части, сосуд имел невысокое горло и вертикальную ручку. Тулово кувшинчика украшено горизонтальными поясками лака красного цвета. Авторами публикации данный сосуд был отнесен к продукции Милета и датирован первой половиной VI в. до н. э. [Копылов, Коваленко, 2006, с. 183-184].

В заключении отметим, что первые памятники раннескифского времени, видимо, появляются на островной части дельты Дона в конце VII в. до н. э. и существуют до середины VI в. до н.э. (рис. 1) Хотя время существования крестовидных блях, подобных обнаруженным в дельте Дона, выходит за пределы первой половины VI в. до н.э., тот факт, что они были обнаружены вне комплексов, не позволяет достоверно говорить о времени их бытования на рассматриваемой территории. В целом нужно отметить, что хронология раннескифских комплексов островной части дельты укладывается во временные рамки существования раннескифской культуры на Нижнем Дону. 


\section{ИЛЛЮСТРАЦИИ}

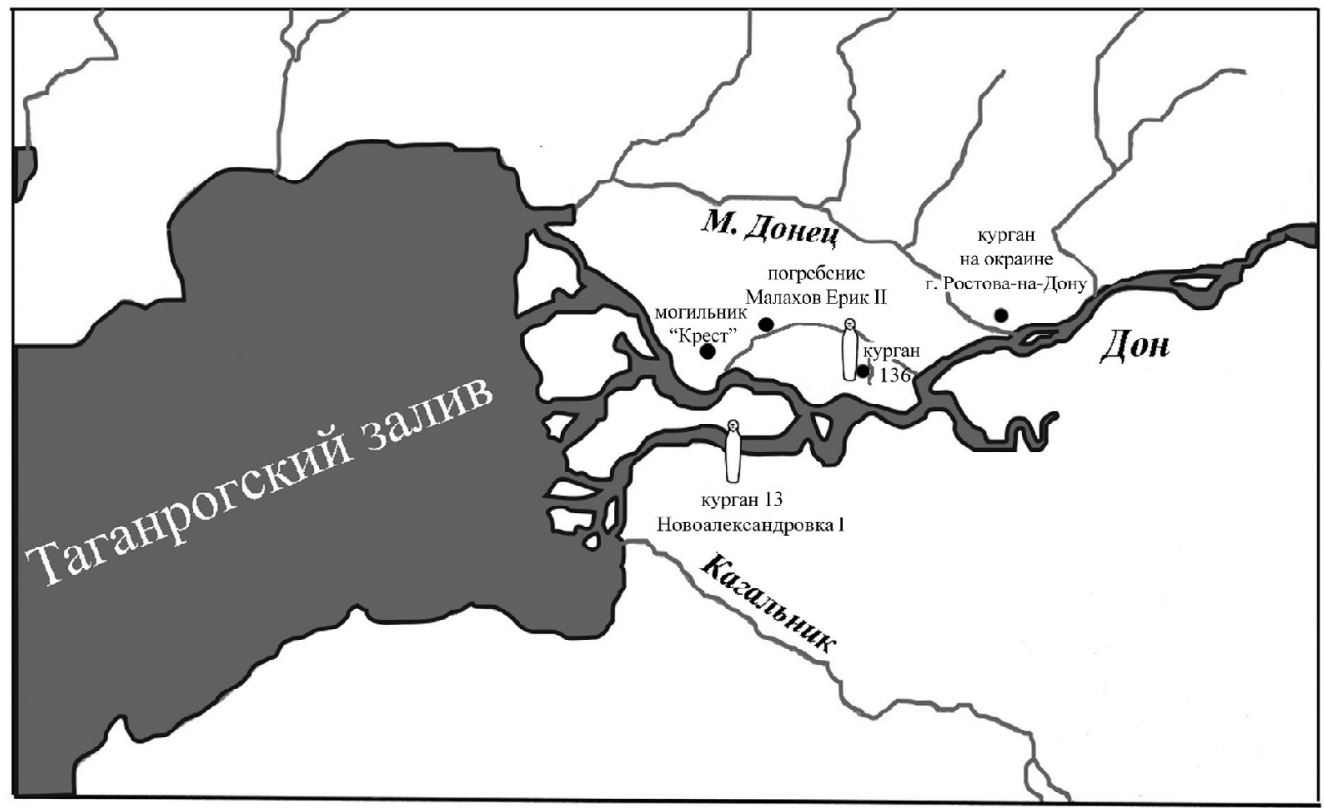

- - раннескифские погребальный комплексы

- скифские антропоморфные изваяния

Рис. 1. Карта-схема расположения раннескифских погребальных памятников в островной части Дельты Дона

Fig. 1. Chart of Early Scythian burial sites in the insular area of the Don river delta 


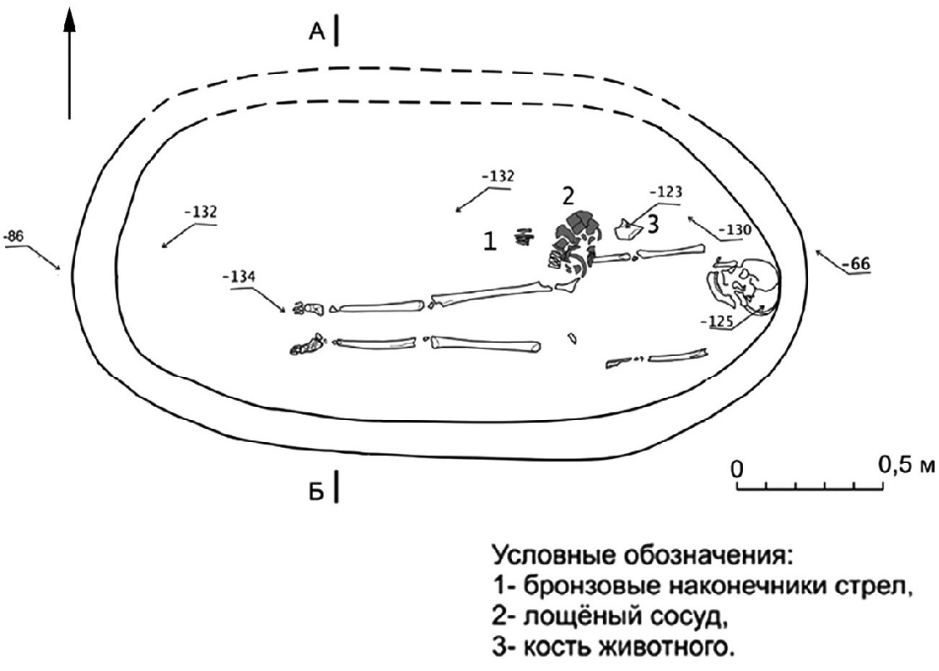

1
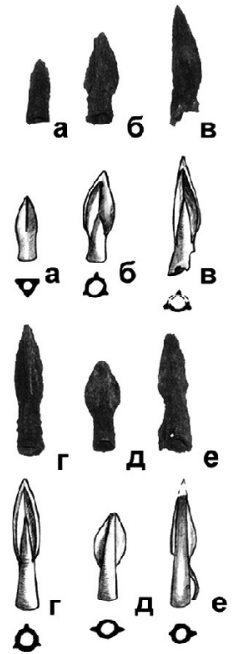

2



3

Рис. 2. Погребальный комплекс Малахов Ерик II [Копылов, Коваленко, 2006]:

1 - план погребения; 2 - колчанный набор; 3 - лепной лощеный сосуд

Fig. 2. The Malakhov Erik II burial complex [Kopylov, Kovalenko, 2006]:

1 - plan of the burial; 2 - quiver set; 3 - handmade polished vessel 

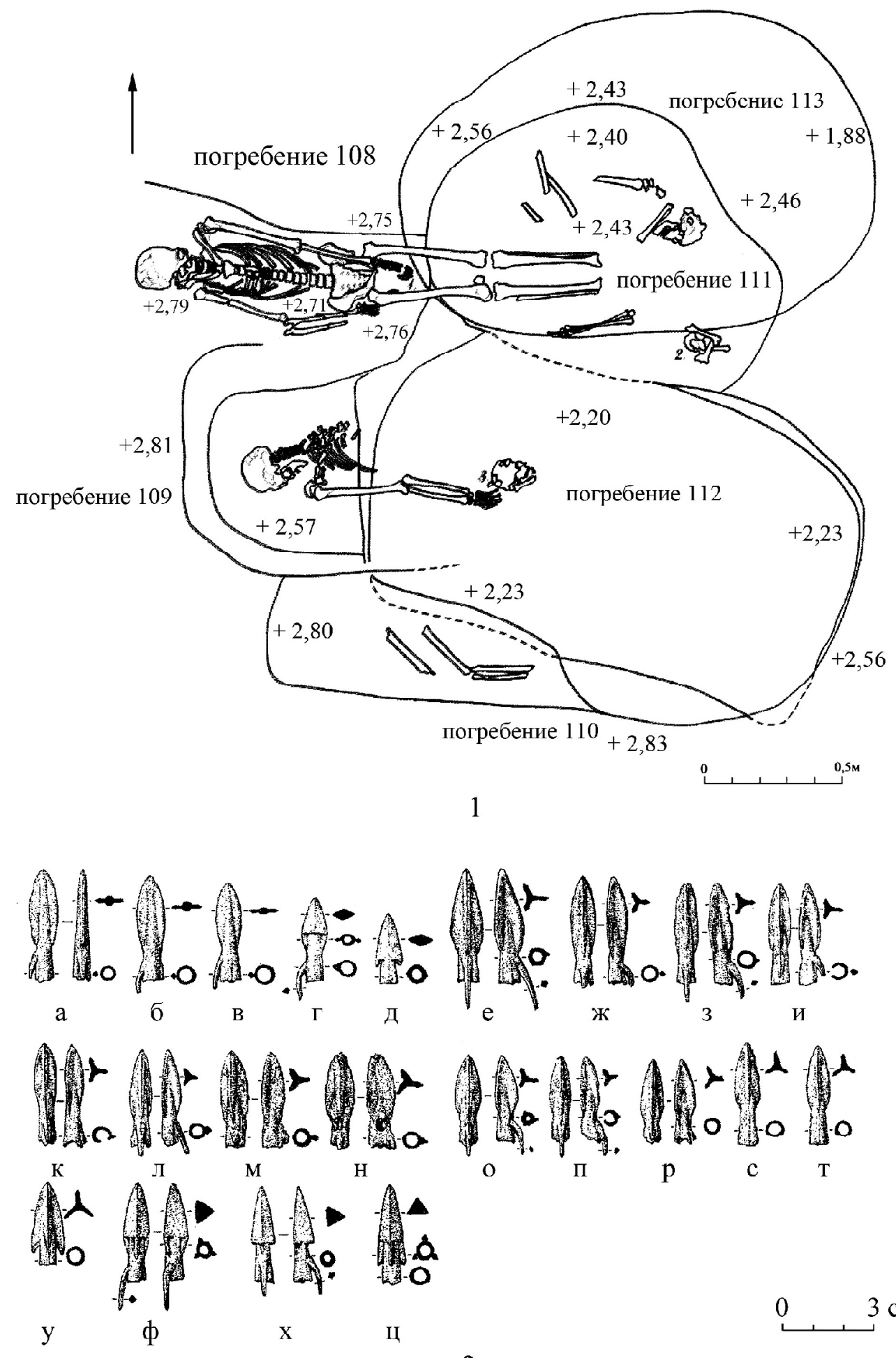

$$
2
$$

2

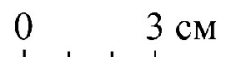

Рис. 3. Могильник «Крест» [Прокофьев, 2014]:

1 - план погр. 108; 2 - колчанный набор погр. 108

Fig. 3. The Krest burial mound [Prokofyev, 2014]:

1 - plan of the burial 108; 2 - quiver set from burial 108 


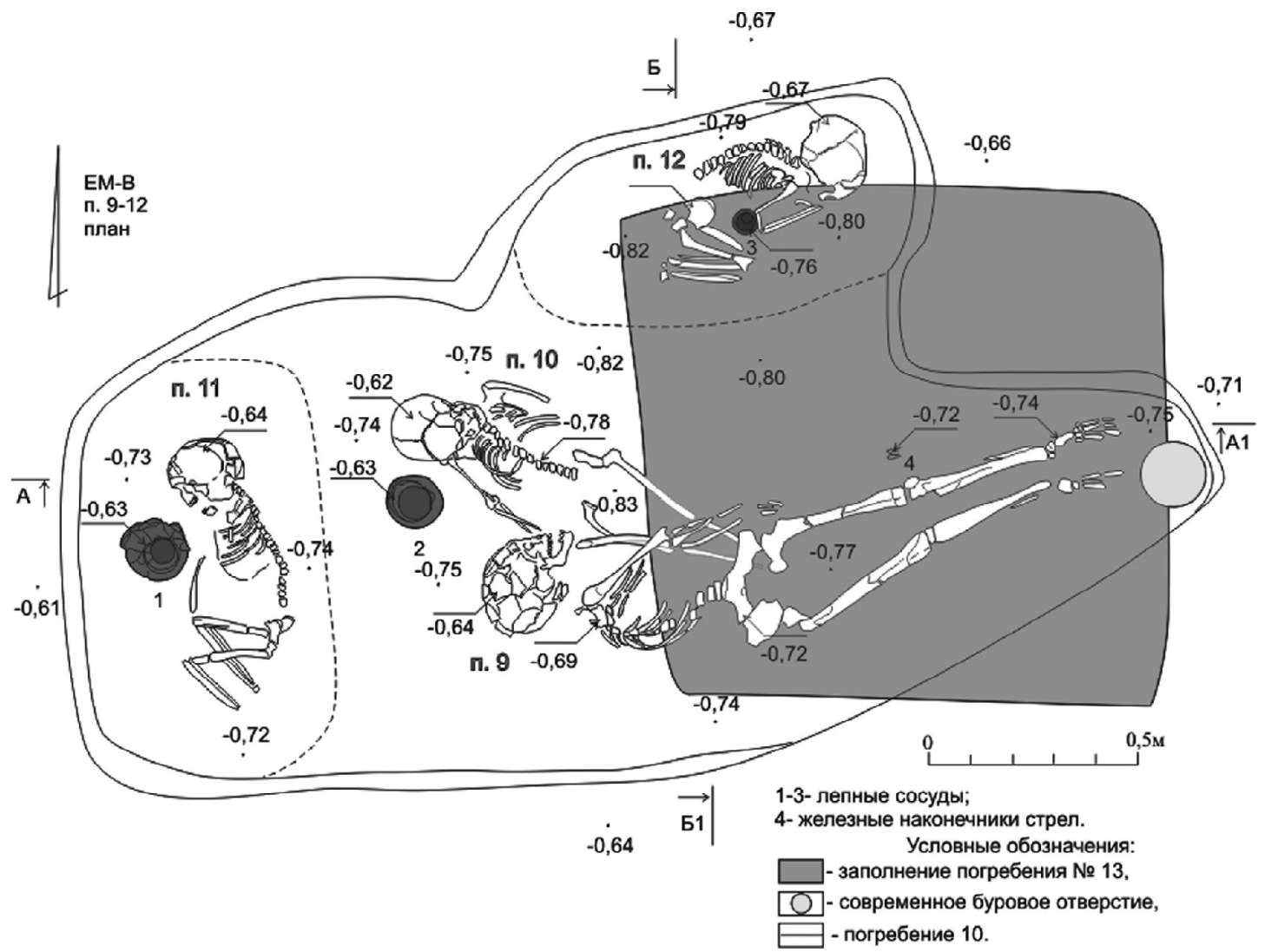

1

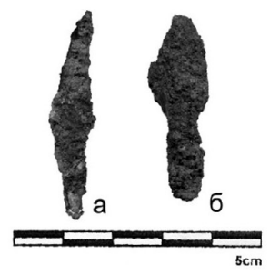

2

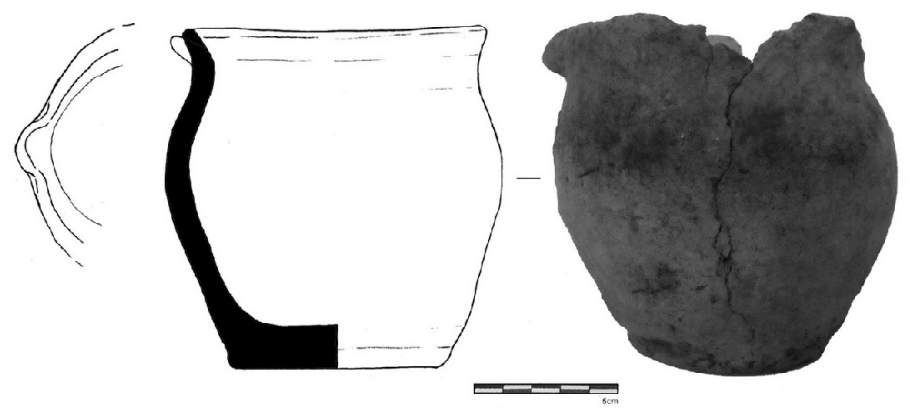

3

Рис. 4. Курган 136 Елизаветовского могильника [Копылов, Русаков, 2015]:

1 - план погр. 9, 10, 11, 12; 2 - колчанный набор погр. 9; 3 - лепной горшок из погр. 10

Fig. 4. Barrow 136 of the Elizavetovskiy burial mound [Kopylov, Rusakov, 2015]:

1 - plan of burials $9,10,11,12 ; 2$ - quiver set from burial 9; 3 - handmade pot from burial 10 


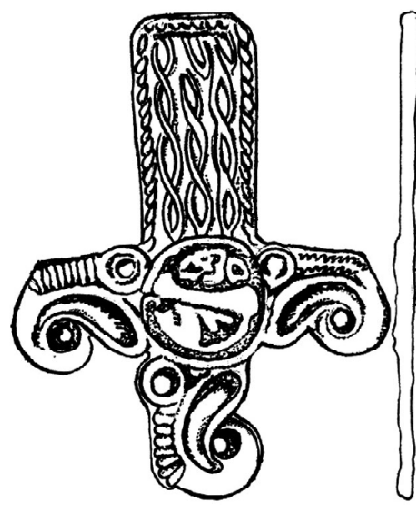

1

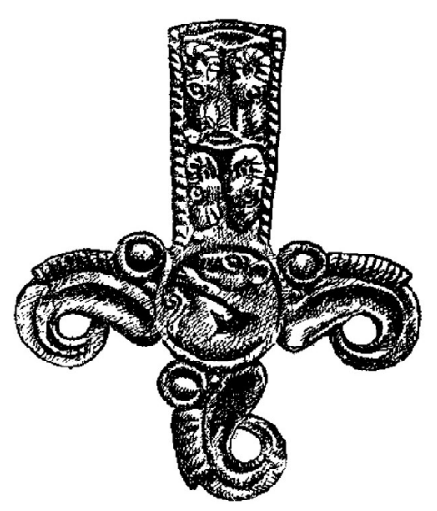

4

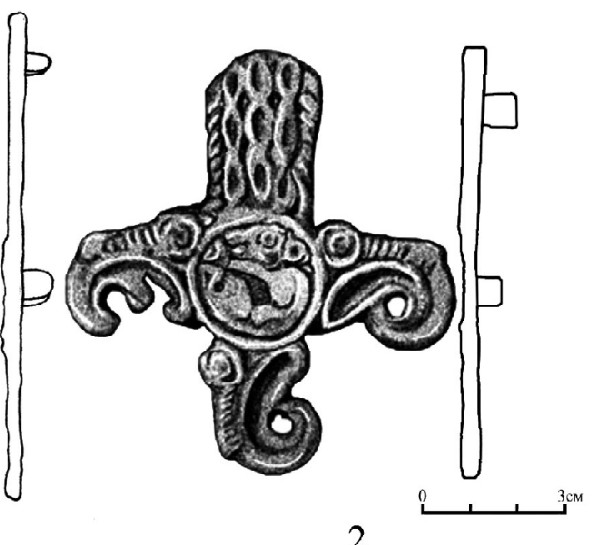

2

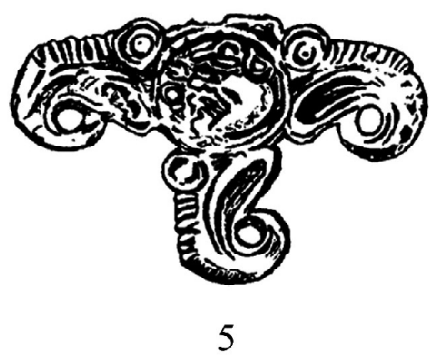

5
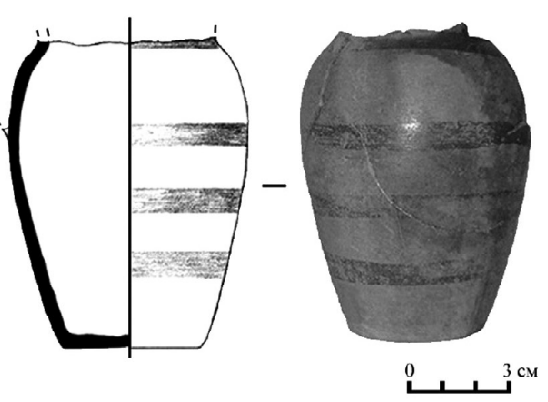

3

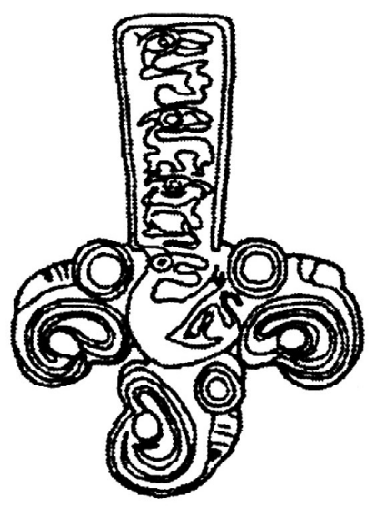

6

Рис. 5. Бронзовые крестовидные бляхи из комплексов раннескифского времени Северного Причерноморья:

1 - бронзовая крестовидная бляха, обнаруженная у х. Дугино;

2 - бронзовая крестовидная бляха, обнаруженная у х. Полушкино [Ильюков, 2016];

3 - красноглиняный ионийский кувшинчик [Копылов, Коваленко, 2006];

4 - бронзовая крестовидная бляха из Ольвийского некрополя [Граков, 1947];

5 - бронзовая крестовидная бляха из погр. 3 кург. 3 Аксай-І [Дьяченко и др., 1999]; 6 - бронзовая крестовидная бляха из могильника Бырсешти [Берчу, 2008]

Fig. 5. Bronze cross plaques from the Early Scythian complexes located in the Northern Black Sea region:

1 - bronze cross plaque from the farmstead Dugino;

2 - bronze cross plaque from the farmstead Polushkino [Ilyukov, 2016];

3 - red-clay Ionian juglet [Kopylov, Kovalenko, 2006];

4 - bronze cross plaque from the Olbian necropolis [Grakov, 1947];

5 - bronze cross plaque from burial 3, barrow 3 (Aksay-I burial mound) [Dyachenko, et al.];

6 - bronze cross plaque from the Byrseshti burial mound [Berchu, 2008] 


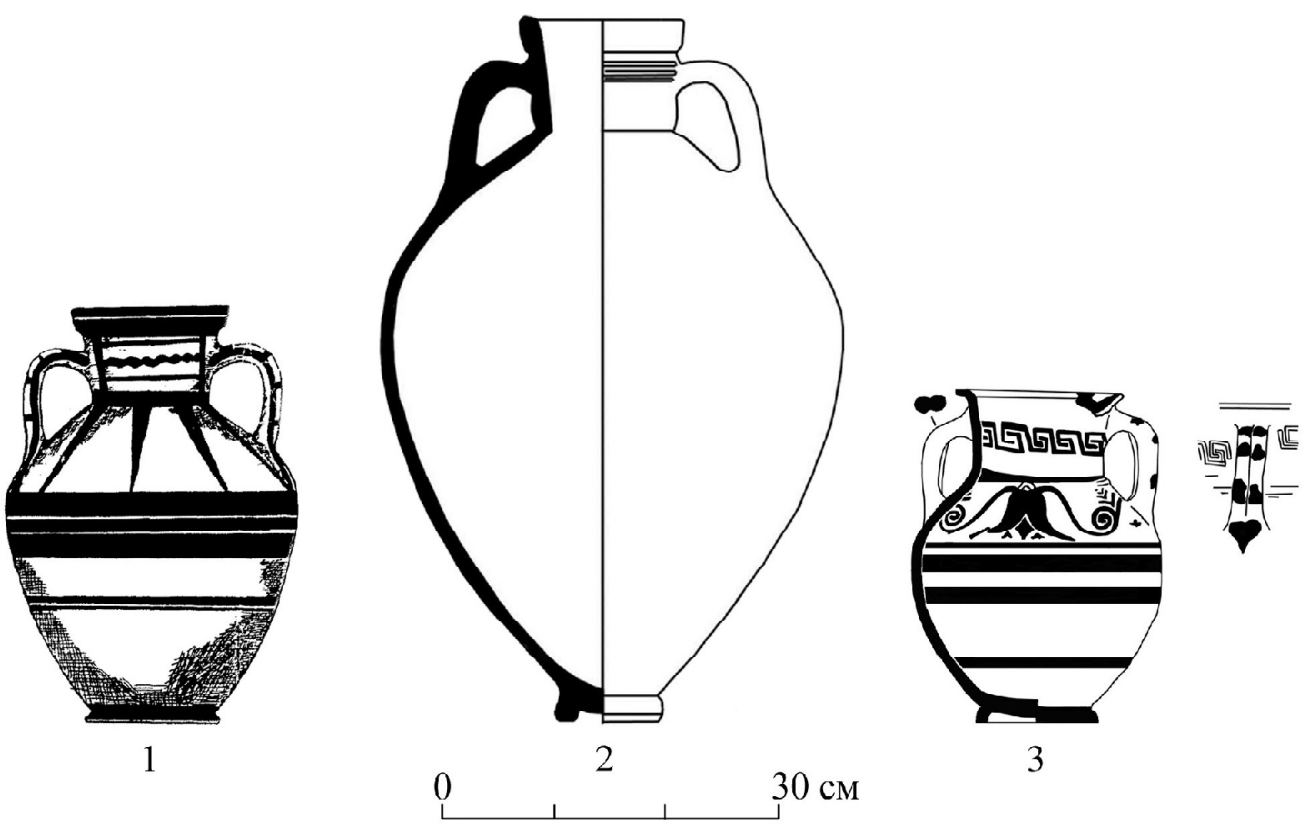

Рис. 6. Импортная греческая керамика из погребений раннескифского времени:

1 - амфора из погр. 10 кург. 2 могильника Бушуйка;

2 - амфора из погр. 8 кург. 7 могильника Новоалександровка-І [Кореняко, Лукьяшко, 1982];

3 - амфора из погр. 3 кург. 3 могильника Аксай-І [Дьяченко и др., 1999]

Fig. 6. Imported Greek ceramics from the Early Scythian burials:

1 - amphora from burial 10, barrow 2 (Bushuyka burial mound);

2 - amphora from burial 8, barrow 7 (Novoaleksandrovka-I burial mound) [Korenyako, Lukyashko, 1982];

3 - amphora from burial 3, barrow 3 (Aksay-I burial mound) [Dyachenko, et al., 1999] 


\section{ПРИМЕЧАНИЯ}

${ }^{1}$ Публикация подготовлена в рамках реализацииГЗ ЮНЦРАНна 2018 г., №гр. проекта 01201354248.

${ }^{2}$ Некоторые исследователи не согласны с интерпретацией данного памятника как могильника, расположенного на дюне, и склонны считать его курганом [Копылов, Русаков, 2017, с. 284, 286].

\section{СПИСОК ЛИТЕРАТУРЫ}

Алексеев А. Ю., 2003. Хронография Европейской Скифии VII-IV вв. до н.э. СПб. : Изд-во Гос. Эрмитажа. 416 с.

Берчу Д., 2008. Даки. Древний народ Карпат и Дуная. М. : Центрполиграф. 192 с.

Брашинский И. Б., 1973. Раскопки скифских курганов на Нижнем Дону // Краткие сообщения института Археологии. Вып. 133. М. С. 54-62.

Граков Б. Н., 1947. Чи мала Ольвія торговельні знасини з Поволжям і Приураллям в архаичну і классичну епохи? // Археология. Сб. Ин-та археології АН УкрССР. Київ. С. 23-38.

Дараган М. Н., 2010. О датировке амфоры из погребения № 2 Репяховатой могилы // Античный мир и археология. Вып. 14. Саратов : Изд-во СГУ им. Н.Г. Чернышевского. С. 175-202.

Дьяченко А. Н., Мейб Э., Скрипкин А. А., Клепиков В. М., 1999. Археологические исследования в Волго-Донском междуречье // Нижневолжский археологический вестник. Вып. 2. С. 93-126.

Ильюков Л. С., 2016. Крестовидные бляхи раннего железного века из степей Восточной Европы // Кавказ и степь на рубеже эпохи поздней бронзы и раннего железа : материалы Междунар. науч. конф., посвященный памяти Марии Николаевны Погребовой (Москва, 2527 апреля 2016 г.). М. : ИВ РАН. С. 80-84.

Капошина С. И., 1956. О скифских элементах в культуре Ольвии // Ольвия и Нижнее Побужье в античную эпоху. Материалы и исследования по археологии. № 50. М., Л. С. 154-189.

Копылов В. П., 1992. Новые данные о связях населения дельты Дона в V в. до н.э. // Донские древности. Вып. 1. Азов. С. 78-87.

Копылов В. П., 2001. Амфоры архаического периода на Нижнем Дону (последняя треть VII - третья четверть VI вв. до н.э.) // Международные отношения в бассейне Черного моря в древности и средние века : материалы IX Междунар. науч. конф. Ростов-н/Д : Изд-во Рост. пед. ун-та. С. 22-24.

Копылов В. П., 2003. Скифы Нижнего Дона и Северо-Восточного Приазовья (вопросы хронологии и военно-политической истории) // Вестник древней истории. № 1. М. С. 131-140.
Копылов В. П., Коваленко А. Н., 2006. Комплексы архаического времени в дельте Дона // Историко-археологические исследования в Азове и на Нижнем Дону в 2005 г. Вып. 22. Азов. С. $181-186$.

Копылов В. П., Русаков М. Ю., 2014. О верхней хронологической границе колчанных наборов в погребальных комплексах раннескифского времени // Война и военное дело в скифосарматском мире : материалы Междунар. науч. конф., посвященной памяти А.И. Мелюковой (Кагальник, 26-29 апреля 2014 г.). Ростов-н/Д : Изд-во ЮНЦ РАН. С. 91-95.

Копылов В. П., Русаков М. Ю., 2017. Раннескифские погребальные комплексы на островной части Дельты Дона // Старожитності степового Причорномор'я і Криму XX. Запоріжжя. С. 282-293.

Кореняко В. А., Лукьяшко С. И., 1982. Новые материалы раннескифского времени на Левобережье Нижнего Дона // Советская археология. № 3. С. 149-164.

Кузнецова Т. М., 2010. Зеркала Скифии VI-III веков до н.э. Т. 2. М. : ТАУС. 425 с.

Монахов С. Ю., 2003. Греческие амфоры в Причерноморье. Типология амфор ведущих центровэкспортеров товаров в керамической таре: Каталог-определитель. М. : Киммерида ; Саратов : Изд-во Сарат. ун-та. 352 с.

Островерхов А. С., 1994.Звіриний стиль у культурі Ольвії //Археологія. № 2. С. 58-69.

Полидович Ю. Б., 2009. Крестовидная бляха из архаического некрополя Ольвии в контексте скифского «звериного стиля» // Боспорский феномен. Искусство на периферии античного мира : материалы Междунар. науч. конф. (Санкт-Петербург, 1-4 декабря 2009 г.). СПб. : Нестор-История. С. 477-484.

Полін С. В., 1987. Хронологія ранньоскіфських пам'яток // Археологія. Вип. 59. С. 17-36.

Прокофьев Р. В., 2014. Раскопки ухугора Дугино в дельте Дона в 2009 году. Ростов-н/Д : Альтаир. 398 с.

Cook R. M., Dupont P., 1999. East Greek pottery. L. ; N. Y.226 p.

Sezgin Y., 2012. Arkaik Dönem Ýonia Üretimi Ticar i Amphoralar. İstanbul. 344 s.

\section{REFERENCES}

Alekseev A.Yu., 2003. The Chronography of European Scythia $\left(7^{\text {th }}-4^{\text {th }}\right.$ centuries BC). Saint Petersburg, The State Hermitage Publ. 416 p. (in Russian). Berchiu D., 2008. The Dacians. The Ancient People of the Carpathians and the Danube. Moscow, Tsentrpoligraf Publ. 192 p. (in Russian). 
Brashinskiy I.B., 1973. Excavations of Scythian Barrows in the Lower Don region. Kratkie soobshcheniya Instituta arkheologii, iss. 133. Moscow, pp. 54-62. (in Russian).

Grakov B.N., 1947. Did Olbia have trade relations with the Volga and Ural Regions in the Archaic and Classical Periods? Arkheologiya. Sbornik Instituta arheologï AN UkrSSR. Kiev, pp. 23-38. (in Ukrainian).

Daragan M.N., 2010. On the Dating of the Amphora from Burial 2 in the Repyakhovataya Grave. Antichnyy mir i arkheologiya. Iss. 14. Saratov, Izd-vo SGU im. N.G. Chernyshevskogo, pp. 175202. (in Russian).

Dyachenko A.N., Meyb E., Skripkin A.A., Klepikov V.M., 1999. Archaeological Studies in the Volga-Don Interfluve. The Lower Volga Archeological Bulletin, iss. 2, pp. 93-126. (in Russian).

Ilyukov L.S., 2016. Cross-Shaped Plaques of the Early Iron Age from the Steppes of Eastern Europe. Kavkaz i step na rubezhe epokhi pozdney bronzy $i$ rannego zheleza: materialy Mezhdunarodnoy nauchnoy konferentsii, posvyashchennoy pamyati Marii Nikolaevny Pogrebovoy (Moskva, 25-27 aprelya 2016 g). Moscow, Institut vostokovedeniya RAN, pp. 80-84. (in Russian).

Kaposhina S.I., 1956. On the Scythian Elements in the Olbian Culture. Olviya i Nizhnee Pobuzhye v antichnuyu epokhu: Materialy i issledovaniya po arkheologii, no. 50. Moscow; Leningrad, pp. 154-189. (in Russian).

Kopylov V.P., 1992. New Data about Connections of the Don River Delta Population in the $5^{\text {th }}$ Century BC. Donskie drevnosti, iss. 1. Azov, pp. 78-87. (in Russian).

Kopylov V.P., 2001. Archaic Amphorae in the Lower Don Region (630 - 525 BC). Mezhdunarodnye otnosheniya $v$ basseyne Chernogo morya $v$ drevnosti $i$ sredniye veka: materialy IX Mezhdunarodnoy nauchnoy konferentsii. Rostov-on-Don, Izd-vo Rost. ped. un-ta, pp. 2224. (in Russian).

Kopylov V.P., 2003. Scythians of the Lower Don and North-East Azov Sea Regions (Chronology and Politico-Military History). Journal of Ancient History, no. 1, pp. 131-140. (in Russian).
Kopylov V.P., Kovalenko A.N., 2006. Archaic Complexes in the Don River Delta. Istorikoarkheologicheskie issledovaniya $v$ Azove $i$ na Nizhnem Donu v 2005 g. Iss. 22. Azov, pp. 181186. (in Russian).

Kopylov V.P., Rusakov M.Yu., 2015. On the Upper Chronological Frame of Quiver Sets in the Early Scythian Burial Complexes. Voyna i voennoe delo $v$ skifo-sarmatskom mire. Materialy Mezhdunarodnoy nauchnoy konferentsii, posvyashchennoy pamyati A.I. Melyukovoy (Kagalnik, 26-29 aprelya 2014 g.). Rostov-onDon, Izd-vo YuNTs RAN, pp. 91-95. (in Russian).

Kopylov V.P., Rusakov M.Yu., 2017. Early Scythian Burial Complexes in the Insular Part of the Don River Delta. Antiquities of Steppe Black Sea Region and Crimea, vol. XX. Zaporizhzhya, pp. 282-293. (in Russian).

Korenyako V.A., Luk'yashko S.I., 1982. New Early Scythian materials from the left bank of the Lower Don. Sovetskaya arkheologiya, no. 3, pp. 149-164. (in Russian).

Kuznetsova T.M., 2010. Mirrors of Scythia of VI-III centuries BC. Vol. II. Moscow, TAUS Publ. 425 p. (in Russian).

Monakhov S. Yu., 2003. Greek amphorae of Black Sea region. Moscow, Kimmerida Publ, Saratov, Izd-vo Saratovskogo universiteta. 352 p.

Ostroverkhov A.S., 1994. Animal Style in the Olbian Culture. Arkheologiya, no. 2, pp. 58-69. (in Ukrainian).

Polidovich Yu.B., 2009. A Cross-Shaped Plaque from Archaic Olbian Necropolis in the Context of Scythian "Animal Style". Bosporskiy fenomen. Iskusstvo na periferii antichnogo mira: materialy Mezhdunarodnoy nauchnoy konferentsii (Sankt-Peterburg, 1-4 dekabrya 2009 g.). Saint Petersburg, Nestor-Istoriya Publ., pp. 477-484. (in Russian).

Polin S.V., 1987. The Chronology of Early Scythian Sites. Arkheologiya, iss. 59, pp. 17-36. (in Ukrainian).

Prokofyev R.V., 2014. Excavations near the Farmstead Dugino in the Don River Delta in 2009. Rostovon-Don, Altair Publ. 398 p. (in Russian).

Cook R.M., Dupont P., 1999. East Greek Pottery. London; New York. $226 \mathrm{p}$.

Sezgin Y., 2012. Ionian trade amphorae of archaic period. Istanbul. 344 p. (in Turkish). 


\section{Information about the Author}

Mikhail Yu. Rusakov, Junior Researche of Archaeological Laboratory, Department of Humanities Research, Southern Scientific Center, RAS, Prosp. Chekhova, 41, 344006 Rostov-on-Don, Russian Federation, rusakov@ssc-ras.ru.

\section{Информация об авторе}

Михаил Юрьевич Русаков, младший научный сотрудник лаборатории археологии, отдел гуманитарных исследований, Южный научный центр РАН, просп. Чехова, 41, 344006 г. Ростов-наДону, Российская Федерация, rusakov@ssc-ras.ru. 